\title{
Near fatal asthma attacks: the reliability of descriptive information collected from close acquaintances
}

\author{
D A Campbell, G McLennan, J R Coates, P A Frith, P A Gluyas, K M Latimer,
} A J Martin, D M Roder, R E Ruffin, D Scarce, P M Yellowlees

Thoracic Medicine Unit, The Queen Elizabeth Hospital, Woodville Road, Woodville South, South Australia, 5011 D A Campbell

P A Gluyas

R E Ruffin

Department of Thoracic Medicine, Royal Adelaide Hospital, North

Terrace, Adelaide,

South Australia, 5000

G McLennan

Royal Australian

College of General

Practitioners (South

Australia Faculty),

15 Gover Street,

North Adelaide,

South Australia, 5006

J R Coates

Respiratory Unit, Repatriation General Hospital, Daws Road,

Daw Park, South

Australia, 5042

P A Frith

Respiratory Unit, Flinders Medical Centre, Flinders

Drive, Bedford Park,

South Australia 5042

K M Latimer

Paediatric

Pulmonology Unit,

Adelaide Children's

Hospital, King

William Road,

North Adelaide,

South Australia, 5006

A J Martin

Epidemiology Branch, South Australian

Health Commission,

Hindmarsh Square,

Adelaide, South

Australia 5000

D M Roder

D Scarce

South Australian Mental Health

Services, PO Box 319,

Felixstowe, South

Australia, 5070

P M Yellowlees

Reprint requests to:

Dr D A Campbell

Received 20 October 1992

Returned to authors

29 December 1992

Revised version received

8 March 1993

Accepted 17 June 1993

\begin{abstract}
Background-The reliability of information collected from close acquaintances of the deceased in studies on mortality from asthma has not been assessed. As part of a South Australian asthma mortality study, levels of agreement for information obtained directly from cases-that is, cases who had experienced near fatal asthma attacks-were compared with corresponding information concerning these cases obtained independently from close acquaintances. Methods-The first 51 subjects presenting from the outset of the main study to hospital accident and emergency departments with near fatal asthma attacks were included to gain an early assessment of the reliability of responses. The level of agreement between self reported information and that obtained from close acquaintances was compared by means of a kappa statistic or intraclass correlation coefficient, depending on the measurement scale. Both score one for complete agreement and zero when there is no agreement.
\end{abstract}

Results-High levels of agreement were found for questions relating to use of hospital services, with agreement levels ranging from 0.92 for visits in the past month to accident and emergency departments, to 0.86 for prior hospital admissions and 0.78 for prior need for assisted ventilation. Levels of agreement for drug treatment ranged from 1.00 for use of $\beta$ agonists to 0.64 for corticosteroid use, and to a low 0.24 for use of sodium cromoglycate. There was moderate agreement for histories of regular use of over the counter medications without a medical consultation $(0 \cdot 57)$. Psychiatric characteristics showed moderate levels of agreement, with values of 0.44 for personal history of psychiatric consultations and 0.50 for denial score. Agreement scores were $\mathbf{0 . 6 6}$ for doctor visits in the past month, 0.66 for limitations in daily activities, 0.76 for loss of work days in the past month, 0.59 for severity of asthma, and 0.55 for frequency of asthma attacks in the past month. Poorer agreement scores were found for trends in asthma symptoms $(0 \cdot 21)$ and frequency of symptoms during the past three years $(0 \cdot 12)$. Sleep disturbance was also associated with a low agreement score $(0 \cdot 25)$.

Conclusions-The more visible the asthma manifestation, and the more recent the period to which it applies, the more reliable is the information provided by close acquaintances. These factors need to be taken into account when using information from close acquaintances in asthma mortality studies.

(Thorax 1993;48:1099-1104)

In response to concerns about increasingly high reported levels of asthma mortality in Australia in the decade to $1988,{ }^{1}$ we examined the accuracy of asthma death certification in South Australia ${ }^{2}$ by methods similar to those employed in corresponding studies in the United Kingdom, New Zealand, and Victoria. ${ }^{3-5}$

In these earlier studies, household or other close acquaintances were used as proxy respondents for the deceased to obtain information concerning the dead subjects' prior asthma histories, including the severity of the asthma and approaches to its management. Generally, however, the reliability of information from these proxy sources was not assessed and this aspect could not be taken into account when interpreting the results.

We undertook an assessment of the reliability of information obtained from proxy sources in this South Australian asthma mortality study by obtaining information by interview from 51 subjects who had experienced near fatal asthma attacks and who had presented to the accident and emergency departments of Adelaide teaching hospitals. This same information was also sought independently, by interview, from a household or other close acquaintance.

A previous New Zealand study of mortality from asthma had indicated that patients dying from asthma had a high frequency of previous near fatal asthma attacks. ${ }^{6}$ We suspected, therefore, that the results on reliability obtained for our sample of near fatal asthma cases may be indicative of those that 
would apply for asthmatic patients experiencing a fatal episode.

Psychosocial features were included in the present reliability assessment and in the broader mortality study, because of prior evidence that these features may contribute to death from asthma. ${ }^{67}$

\section{Methods}

The present investigation of the reliability of information obtained from proxy sources was part of a broader study of asthma mortality, the details of which have been reported elsewhere. ${ }^{2}$ The study was conducted under the auspices of the South Australian Branch of the Thoracic Society of Australia and New Zealand with the approval of institutional ethics committees of participating hospitals.

The first 51 subjects presenting with a near fatal asthma attack to the accident and emergency departments of Adelaide teaching hospitals from the outset of the study were recruited for this assessment of reliability. The main purpose was to gain an early assessment of the reliability of measures in the main study. It was considered that the sample size for this assessment would provide sufficient power to show that levels of agreement differed significantly $(p<0.05)$ from zero, because correlations between the pairs of responses of around 0.50 were anticipated. This sample size allowed for some attrition where acquaintances did not consider themselves sufficiently informed to provide a response.

To qualify for this investigation, subjects were required to have experienced either respiratory arrest due to severe asthma, or severe asthma with a $\mathrm{PaCO}_{2}$ greater than $50 \mathrm{~mm} \mathrm{Hg}$ $(6.5 \mathrm{kPa})$, or an altered conscious state or inability to speak on presenting to hospital, or both. Patients meeting these criteria, we considered, were likely to have experienced a near fatal attack of asthma. ${ }^{8}$

A respiratory nurse held personal structured interviews with these asthma cases, and independently with their household or other close acquaintances, as soon as practicable after their discharge from hospital. The closest, most readily available acquaintance was used. Of the close acquaintances interviewed, $49(96 \%)$ lived in the same house, and of these, $45(92 \%)$ were relatives. The others were close friends or relatives not living in the same house. All interviews with cases and acquaintances were carried out face to face. The median time that elapsed between the asthma attack and the interview was 13 days for the cases and 23 days for their acquaintances.

The interview questionnaire used in the earlier Victorian and New Zealand asthma mortality studies ${ }^{45}$ was used, with little modification, to obtain information on personal details, and history, severity, and management of asthma. The questions relevant to the present reliability study are shown in the appendix. A structured process incorporating the interview questionnaire and prompts was followed strictly and uniformly to ensure that comparable data were obtained from the two groups. The professional experience of the single interviewer and her adherence to a predetermined protocol is considered to have minimised the potential for bias, including recall bias.

Questions on psychiatric characteristics were also included because of previous evidence of a high level of psychiatric morbidity

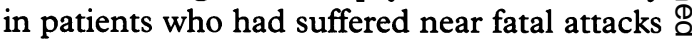
of asthma. ${ }^{9}$ These questions included the denial scale of a previously used illnessbehaviour questionnaire, ${ }^{10}$ and also additional questions directed at personal history of psychiatric consultations.

\section{STATISTICAL METHODS}

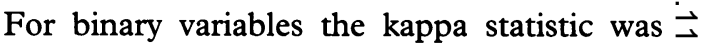
used as a measure of agreement between $\overrightarrow{0}$ cases and their acquaintances. ${ }^{11}$ Kappa mea- $\mathscr{\&}$ sures the amount of agreement beyond that 을 expected by chance, as a proportion of the maximum agreement beyond chance- $z$ namely, observed - expected/1 - expected. Thus kappa equals one for perfect agreement, and zero for no agreement beyond that which $\stackrel{\mathbb{D}}{-}$ may be expected by chance. Negative kappa $\overrightarrow{0}$ values are possible, indicating that there is even less agreement than would be expected by chance.

For ordinal and continuous variables the intraclass correlation coefficient (ICC) was preferred. ${ }^{12}$ The ICC is a measure similar to kappa. It was calculated with mean square terms from a two way analysis of variance of $\frac{0}{3}$ subjects by information source (case or acquaintance). The intraclass correlation coefficient ranges from zero for no agreement to one for perfect agreement.

McNemar and Wilcoxon matched pairs signed rank tests were used for binary and $\overline{3}$ ordinal or continuous variables, respectively, to indicate whether there were statistically significant $(\mathrm{p}<0.05)$ differences between the aggregate responses of cases and their acquaintances. ${ }^{13}$ When there were fewer than $\frac{D}{0}$ 10 untied responses, the exact test for paired responses was substituted for the McNemar o test. $^{13}$

The levels of agreement as indicated by kappa or ICC scores were subsequently graded from poor to high as described by Landis. ${ }^{14}$ Also, 95\% confidence intervals $\stackrel{\mathbb{D}}{\mathscr{D}}$ (95\% CIs) were used to indicate levels of sta- ? tistical precision. If the lower value was less than zero, the association was considered not to be statistically significant. ${ }^{15}$

\section{Results}

The 51 study subjects comprised 29 men and 22 women of mean age 41 (range 15 to 74 ) years. The figure shows their distribution by age and sex. The responses of cases, and of their close acquaintances, are presented by subject category. Table 1 shows the aggregate responses of cases and acquaintances. 
Table 1 Aggregate responses of cases and acquaintances for characteristics of cases

\begin{tabular}{|c|c|c|}
\hline Characteristic & Cases (\%) & Acquaintances (\%) \\
\hline \multicolumn{3}{|l|}{ Asthma history: } \\
\hline Weekly symptoms in past three months & 72 & 76 \\
\hline Monthly attacks in past 12 months & 49 & 45 \\
\hline Weekly attacks in past month & 38 & 42 \\
\hline No limitations to daily activities, or only with & & \\
\hline sport or on stairs & 67 & 65 \\
\hline Sleep disturbance & 81 & 85 \\
\hline No days lost from work or other usual daily & & \\
\hline activity in last month & 65 & 58 \\
\hline Severity of asthma rating of severe & 55 & $35^{\star}$ \\
\hline \multicolumn{3}{|l|}{ Use of medications: } \\
\hline$\beta$ agonist (inhaled) & 100 & 100 \\
\hline Corticosteroid (oral and inhaled): & 61 & 55 \\
\hline Inhaled corticosteroids & 53 & $43^{\star}$ \\
\hline Oral corticosteroids & 24 & 27 \\
\hline Xanthine (oral) & 78 & $65^{\star}$ \\
\hline Sodium cromoglycate (oral) (few cases) & 10 & 4 \\
\hline Over the counter medication (inhaled $\beta$ agonist) & 28 & 28 \\
\hline \multicolumn{3}{|l|}{ Health services: } \\
\hline Admission to hospital (ever) & 73 & 71 \\
\hline Admission to hospital (past 12 months) & 39 & 41 \\
\hline Admission to intensive care unit (ever) & 28 & 20 \\
\hline Attendance or accident and emergency (last month) & 8 & 6 \\
\hline Visits to doctor (last month) & 57 & 55 \\
\hline Previous assisted ventilation (ever) & 8 & 13 \\
\hline \multicolumn{3}{|l|}{ Psychiatric features: } \\
\hline Denial score ( 3 to 5$)$ & 80 & 82 \\
\hline Personal psychiatric care & 18 & 23 \\
\hline
\end{tabular}

For most of these aggregate responses the difference between cases and acquaintances did not approach significance $(p>0 \cdot 20)$.

^For severity of asthma rated as mild, moderate, or severe, there was a significant difference between the responses (Wilcoxon: $p<0.05$ ). Responses for use of xanthine were also significantly different $(p<0.05)$, as were responses for use of inhaled corticosteroids $(\mathrm{p}<0.05)$.
The highest statistically significant levels of agreement for history of asthma were for limitations to daily activities and for days lost from work or usual activity in the past month.

When considered in aggregate (table 1) most of the characteristics of history of asthma showed no statistically significant difference when the responses of cases and acquaintances were compared $(p>0 \cdot 20)$. There was, however, a statistically significant difference for severity of asthma (Wilcoxon: $\mathrm{p}<0.05$ ), with the cases of asthma being rated as severe by a higher proportion of cases $(55 \%)$ than acquaintances $(35 \%)$.

\section{REGULAR USE OF MEDICATIONS}

From table 3 it is evident that a very high level of agreement applied to the use of $\beta$ agonists, the reported use being $100 \%$ by both cases and acquaintances. Relatively high levels of agreement were reported for the use of both oral and inhaled corticosteroid medication. Whereas the point estimate was higher for inhaled than oral corticosteroid use, the level of agreement was statistically significant in both instances. By comparison, there was a lower level of agreement suggested for use of oral xanthines, although this agreement also was statistically significant.

There was a fairly high and statistically significant level of agreement for use of inhaled $\beta$ agonists obtained over the counter from a pharmacist, without doctor consultation. By comparison, a poor level of agreement existed between cases' and acquaintances' reports of use of sodium cromoglycate, although the reported use of this drug by cases was rare (five cases only).

Table 1 shows the differences in cases' and acquaintances' scores when compared in aggregate. There were no statistically significant differences, except for the use of xanthines, where $78 \%$ of cases and $65 \%$ of acquaintances reported this use $(p<0.05)$, and the use of inhaled corticosteroids which was reported to be $53 \%$ by cases and $43 \%$ by acquaintances $(p=0.05)$.

\section{USE OF HEALTH SERVICES}

Table 4 shows the levels of agreement found between the near fatal asthma cases and their close acquaintances for the use of the various health services.

Highest agreements were found for accident and emergency department visits over the past month, and for ever having a hospital admission for asthma. Fairly high levels of agreement also were found for having a hospital admission over the last 12 months, and for history of assisted ventilation for asthma. Moderate levels of agreement were found in the subject categories of doctor visits over the past month, and for ever having an intensive care unit admission for asthma. In all these instances of utilisation of the health service, the level of agreement was statistically significant.

Table 1 shows the aggregate responses by cases and acquaintances. There were no statistically significant differences $(p>0 \cdot 20)$. 
Table 2 Agreement between responses of patients with a near fatal attack of asthma and their close acquaintances for history and severity* of patients' asthma

\begin{tabular}{|c|c|c|c|}
\hline Characteristic & Classification & $\begin{array}{l}\text { Cases } \\
\text { with paired } \\
\text { responses (n) }\end{array}$ & $\begin{array}{l}\text { Agreement† } \\
(95 \% \text { CI })\end{array}$ \\
\hline $\begin{array}{l}\text { Trends in symptoms } \\
\text { in past three years }\end{array}$ & Improving; unchanged; deteriorating & 50 & $0.21(-0.07$ to 0.46$)$ \\
\hline $\begin{array}{l}\text { Frequency of } \\
\text { symptoms in past } \\
\text { three years }\end{array}$ & $\begin{array}{l}\text { Weekly in last three months; less than weekly; } \\
\text { not in last three months; not in last three years }\end{array}$ & 50 & $0.12(-0.16$ to 0.38$)$ \\
\hline $\begin{array}{l}\text { Frequency of attacks } \\
\text { in past year }\end{array}$ & $\begin{array}{l}\text { At least weekly; at least monthly; at least three } \\
\text { attacks; less than three attacks; none }\end{array}$ & 47 & $0.47(0.22$ to 0.67$)$ \\
\hline $\begin{array}{l}\text { Frequency of attacks } \\
\text { in past month }\end{array}$ & At least weekly; less frequently; none & 48 & $0.55(0.32$ to 0.72$)$ \\
\hline $\begin{array}{l}\text { Limitations to daily } \\
\text { activities }\end{array}$ & $\begin{array}{l}\text { During active sport; climbing stairs; hurrying on flat; } \\
\text { walking on flat (own pace); dressing; none }\end{array}$ & 49 & $0.66(0.47$ to 0.79$)$ \\
\hline Sleep disturbance & Yes; no & 47 & $0.25(0.12$ to 0.61$)$ \\
\hline $\begin{array}{l}\text { Days lost from work } \\
\text { or usual activity in } \\
\text { past month }\end{array}$ & Days & 48 & $0.76(0.61$ to 0.86$)$ \\
\hline Severity of asthma & Mild; moderate; severe & 51 & $0.59(0.39$ to 0.75$)$ \\
\hline
\end{tabular}

*51 consecutive cases presenting to accident and emergency departments of Adelaide teaching hospitals with near fatal asthma attacks.

†Agreement estimated with the kappa statistic (binary variables) or intraclass correlation coefficient (ordinal and continuous variables).

\section{PSYCHIATRIC FEATURES}

Table 5 shows a moderate level of agreement for denial score and to a lesser extent for personal history of past psychiatric care. These levels of agreement are statistically significant.

Table 3 Agreement between responses of patients with a near fatal attack of asthma and their close acquaintances for regular medication histories * of patients

\begin{tabular}{llll}
\hline Medication & Classification & $\begin{array}{l}\text { Cases } \\
\text { with paired } \\
\text { responses }(n)\end{array}$ & $\begin{array}{l}\text { Agreement } \\
(95 \% \text { CI) } \dagger\end{array}$ \\
\hline$\beta$ agonists (inhaled) & Yes; no & 51 & 1.00 \\
Xanthines (oral) & Yes; no & 51 & $0.45(0.17$ to 0.72$)$ \\
Corticosteroids (oral or inhaled) & Yes; no & 51 & $0.64(0.39$ to 0.84$)$ \\
Inhaled corticosteroids & Yes; no & 51 & $0.79(0.58$ to 1.00$)$ \\
Oral corticosteroids & Yes; no & 51 & $0.57(0.34$ to 0.80$)$ \\
Sodium cromoglycate (inhaled) & Yes; no & 51 & $0.24(0.06$ to 0.79$)$ \\
$\begin{array}{l}\text { Over the counter medication } \\
\text { (inhaled } \beta \text { agonists) }\end{array}$ & Yes; no & 47 & $0.57(0.26$ to 0.82$)$ \\
\hline
\end{tabular}

$\star$ As for table 2 .

†Agreement estimated with the kappa statistic.

Table 4 Agreement between responses of patients with a near fatal attack of asthma and their close acquaintances on use by the patient of health services for asthma care*

\begin{tabular}{|c|c|c|c|}
\hline Use of health services & Classification & $\begin{array}{l}\text { Cases } \\
\text { with paired } \\
\text { responses (n) }\end{array}$ & $\begin{array}{l}\text { Agreement } \\
(95 \% C I) \dagger\end{array}$ \\
\hline Admission to hospital (ever) & Yes; no & 51 & $0.86(0.68$ to 1.00$)$ \\
\hline $\begin{array}{l}\text { Admission to hospital } \\
\text { (last } 12 \text { months) }\end{array}$ & Yes; no & 46 & $0.77(0.56$ to 0.91$)$ \\
\hline $\begin{array}{l}\text { Admission to intensive care } \\
\text { unit (ever) }\end{array}$ & Yes; no & 50 & $0.57(0.31$ to 0.79$)$ \\
\hline $\begin{array}{l}\text { Visit to accident and emergency } \\
\text { department (last month) }\end{array}$ & Number of visits & 48 & $0.92(0.86$ to 0.95$)$ \\
\hline Visits to doctor (last month) & Number of visits & 47 & $0.66(0.47$ to 0.80$)$ \\
\hline Assisted ventilation & Yes; no & 48 & $0.78(0.38$ to 1.00$)$ \\
\hline
\end{tabular}

* As for table 2 .

These data exclude the current presentation with a near fatal attack of asthma.

Table 5 Agreement between responses of patients with a near fatal attack of asthma and their close acquaintances for psychiatric characteristics * of the patients

\begin{tabular}{llll}
\hline Characteristic & Classification & $\begin{array}{l}\text { Cases with paired } \\
\text { responses }(n)\end{array}$ & $\begin{array}{l}\text { Agreement } \\
(95 \% \text { CI)† }\end{array}$ \\
\hline $\begin{array}{l}\text { Personal history of } \\
\text { psychiatric care }\end{array}$ & Yes; no & 44 & $0.44(0 \cdot 10$ to 0.72) \\
\begin{tabular}{l} 
Denial score \\
\hline
\end{tabular} & 0 to 5 & 44 & $0.50(0.25$ to 0.69) \\
\hline
\end{tabular}

${ }^{\star}$ †As for table 2 .
When considered in aggregate (table 1), denial scores did not differ significantly by information source, with $80 \%$ of cases and $82 \%$ of near acquaintances reporting a denial score of three or more. The mean score for the cases was 3.7 based on cases' reports and 3.6 based on acquaintances' reports.

The proportion of cases reported to have a history of psychiatric consultation was not significantly different when cases' and acquaintances' reports were compared in aggregate.

\section{SMOKING HISTORY}

Information from subjects and acquaintances showed a high level of agreement (kappa $=$ 0.87 ) and this was statistically significant ( $95 \%$ CI 0.72 to 0.96 ).

Taken in aggregate, a history of regular tobacco smoking was reported by $65 \%$ of cases and $67 \%$ of acquaintances, there being $₹$ no statistically significant difference between these proportions.

\section{Discussion}

In studies of deceased subjects, it is generally necessary to obtain information from proxy respondents such as household or other close acquaintances. The reliability and accuracy of $\bullet$ this information needs to be assessed if results $\Phi_{\mathscr{D}}$ are to be interpreted appropriately. The need to assess reliability of information obtained from close acquaintances has been emphasised in care of the aged, cancer care and psychiatric research, ${ }^{15-18}$ but it has received little attention in studies of mortality from asthma.

In the present investigation we studied 8 asthmatic patients experiencing a near fatal attack of asthma because of previous evidence that such subjects were at increased risk of ? death due to asthma. ${ }^{6}$ It seemed likely that results obtained from this group might indicate the quality of information that could be obtained with similar methods to study asthmatic subjects who had died of asthma. 
The study was undertaken to assist in the interpretation of the results of a broader study of mortality from asthma. In so far as it was based on only 51 cases, it was not feasible to compare the reliability of the information obtained by category of close acquaintances, $96 \%$ of whom were household members ( $92 \%$ were family members). It seemed likely to us, however, that the reliability of information obtained from household acquaintances might have been greater than that obtained from those close acquaintances who lived at a greater distance.

The present results indicate that proxy reporting can achieve fair to high levels of agreement with self reporting by asthmatic subjects in relation to doctor visits; utilisation of inpatient and outpatient hospital services; a history of needing assisted ventilation; and the regular use of asthma medications, including $\beta$ agonists, corticosteroids (oral and inhaled in aggregate), and xanthines. It also seems that close acquaintances can be fairly reliable sources of information concerning the level of severity of asthma; days lost from work or other usual daily activity due to asthma; asthma induced limitations on activities of daily living; frequency of asthma attacks for periods extending up to one year; regular use of asthma medications obtained over the counter from the pharmacist without previous medical consultation; and on the psychiatric characteristics relating to denial and history of prior personal psychiatric consultations. Fairly reliable smoking histories may also be obtained by this means.

By comparison, close acquaintances may not be reliable sources of information concerning asthma symptoms for periods extending beyond one year, or on less obvious symptomatic manifestations of asthma such as sleep disturbances. Indeed, the more visible the feature, and the more recent the period to which the question refers, the more reliable may be the information obtained.

Our decision to include psychiatric features seems to have been supported by the data obtained for this small series of cases. About $18 \%$ of cases had a history of psychiatric consultation. This seems to be a high proportion compared with reports of a lifetime prevalence for all psychiatric disorders of about $20 \%$ to $25 \%$ in the general community, ${ }^{19}$ particularly when it is considered that only a small fraction of patients with psychiatric diagnoses actually seek psychiatric treatment. Yellowlees and Kalucy have suggested that asthma itself may be anxiogenic, and that simply having asthma may predispose to developing anxiety disorders. ${ }^{20}$ The denial scores reported in this small study were higher than previously reported for either general practice or psychiatric patients, ${ }^{20}$ which also points to a raised level of psychiatric disorders.

It would seem that psychiatric features should be included in studies of mortality from asthma. Despite the stigma that may be attached to psychiatric consultations, the fair levels of agreement between cases and proxy respondents for such information in this present study suggest that this may be a more reliable element of the medical history than expected.

We consider that studies of death from asthma that use information from close acquaintances of the deceased should in general place greatest reliance on histories of use of health services, and on recent histories of functional and symptomatic state. Information obtained from close acquaintances concerning recent asthma history and category of medication used on a regular basis seems to be comparatively reliable for cases experiencing near fatal asthma attacks. By inference, close acquaintances may also be reliable sources of such information for persons who died from asthma. It may not be possible, however, in a study of deaths from asthma to interview acquaintances as soon as was done in our study.

\section{Appendix}

QUESTIONNAIRE:

This consisted of a subset of relevant questions extracted from the South Australian Asthma questionnaire.

The following questions were asked of the close acquaintance (usually a household family member). The same questions were directed to the patient in the same context, but with the second person singular.

1 How frequent were X's symptoms?

$\mathrm{W}$ : None in past three years

$\mathrm{X}$ : Symptoms in past three years but NOT in past three months

Y: Symptoms in past three months but less than once per week.

$\mathrm{Z}$ : Symptoms in past three months and at least once per week.

2 Over the past three years, have X's symptoms been: improving/deteriorating/staying the same?

3 Has X ever been admitted to hospital in the past for asthma? yes/no

4 Has X ever been admitted to an ICU for asthma? yes/no

5 Did $\mathrm{X}$ ever require assisted ventilation? yes/no

6 How frequent were asthma attacks over the past 12 months? None in past 12 months/less than three in past 12 months/at least three in past 12 months but less than monthly/at least monthly in past 12 months but less than weekly/at least weekly or persistent.

7 How frequent were the attacks over the past month? None/less than weekly/ at least weekly or persistent.

8 Was X limited by asthma or wheeze? Not at all/only with active sport/walking up stairs/hurrying on the flat/walking on the flat/when dressing.

9 Did $X$ have sleep disturbance due to asthma? yes/no

10 How many days had $\mathrm{X}$ lost from school or work in the past month?

11 How many times had $\mathrm{X}$ attended a doctor (for asthma) in the past month? 
12 How many times did $\mathrm{X}$ attend a hospital accident and emergency (casualty) department in the past month?

13 Did $\mathrm{X}$ have a hospital admission in the last 12 months?

14 Did X take any medicine (i.e. tablets, inhalers, injections, suppositories, etc) for asthma? yes/no. If yes, what medications were taken regularly? What medications were taken with symptoms or increase in symptoms?

15 Did X ever smoke tobacco regularly? yes/no

16 Has X used over the counter medications for asthma without medical consultation? yes/no

17 Has $\mathrm{X}$ ever received psychiatric treatment?

This study was conducted under the auspices of the South Australian Branch of the Thoracic Society of Australia and New Zealand and sponsored by the Asthma Foundation of South Australia and the National Health and Medical Research Council. Financial support was obtained from Astra Pharmaceuticals Pty Ltd, Boehringer Ingelheim Pty Ltd, Glaxo Australia Pty Ltd, and Fisons Pharmaceuticals Pty Ltd.

1 Sears MR. Trends in asthma mortality-New Zealand and international experience. In: Ruffin RE, ed. Asthma mortality: proceedings of the second national asthma epidemiology workshop. Sydney: Excerpta Medica, 1990:1-3.

2 Campbell DA, McLennan GW, Coates JR, Frith PA, Gluyas PA, Latimer KM, et al. Accuracy of asthma statistics from death certificates in South Australia. Med 7 Aust 1992;156:860-3

3 British Thoracic Association. Death from asthma in two regions of England. BMF 1982;285:1251-5.

4 Sears MR, Rea HH, Beaglehole R, Gillies AJD, Holst PE,
O'Donnell TV, et al. Asthma mortality in New Zealand: a national study. NZ Med f 1985;98: 271-5.

5 Robertson CF, Rubinfeld AR, Bowes G. Deaths from asthma in Victoria: a twelve month survey. Med $\mathcal{F}$ Aust 1990;152:511-7.

6 Rea HH, Scragg R, Jackson R, Beaglehole R, Fenwick J, Sutherland DC. A case-control study of deaths from asthma. Thorax 1986;41:833-9.

7 Yellowlees PM, Ruffin RE. Psychological defences and coping styles in patients following a life-threatening attack of asthma. Chest 1989;95:1298-303.

8 Ruffin RE, Latimer KM, Schembri DA. Longitudinal study of near-fatal asthma. Chest 1991;99:77-83.

9 Yellowlees PM, Haynes S, Potts N, Ruffin RE. Psychiatric morbidity in patients with life-threatening asthma: initial report of a case-controlled study. Med $\mathcal{F}$ Aust 1988; 149:246-9.

10 Pilowsky I, Spence ND. Manual for the illness-behaviour questionnaire. Adelaide: University of Adelaide Press, 1981.

11 Maclure M, Willett WC. Misinterpretation and misuse of the kappa statistic. Am $\mathcal{f}$ Epidemiol 1987;126:161-9.

12 Morton AP, Dobson AJ. Assessing agreement. Med $\mathcal{F}$ Aust 1989;150:384-7.

13 Armitage P, Berry G, ed. Statistical methods in medical research. Oxford: Blackwell, 1987:121-3.

14 Landis RJ, Koch GG. The measurement of observer $\infty$ agreement for categorical data. Biometrics 1977:33: 159-64.

15 Rothman ML, Hedrick SC, Bulcroft KA, Hickman DH, Rubenstein LZ. The validity of proxy-generated scores as measures of patient health status. Med Care 1991; 29:115-24.

16 Aaronson NK. Methodologic issues in assessing the quality of life of cancer patients. Cancer 1991;67:844-50.

17 Bassett SS, Magaziner J, Hebel JR. Reliability of proxy response on mental health indices for aged, communitydwelling women. Psychol Aging 1990:5:127-32.

18 Magaziner J, Simonsick EM, Kashner TM, Hebel JR. Patient-proxy response comparability on measures of patient health and function status. $f$ Clin Epidemiol 1988;41:1065-74.

19 Robins LN, Helzer JE, Weissman MM, Orvaschel $H$, Gruenberg EE, Burke JD, Regier DA. Lifetime prevalence of specific psychiatric disorders in three sites. Arch Gen Psychiatry 1984;41:949-58.

20 Yellowlees PM, Kalucy RS. Psychobiological aspects of asthma and the consequent research implications. Chest 1990;97:628-34. 